\title{
ECONOMY AND EFFICIENCY IN THE DEPARTMENT OF WATER SUPPLY, GAS AND ELECTRICITY, NEW YORK CITY
}

\section{J. Leggett Pultz,}

In Charge Bureau of Economy and Efficiency, Department of Water Supply, Gas and Electricity, New York City.

This article is written for the purpose of describing the character and scope of the work undertaken to promote economy and efficiency in the Department of Water Supply, Gas and Electricity of New York City.

The terms "economy" and "efficiency" in their application to the department in question involve two intimately related ideas: efficiency, meaning the attainment of a given result with the minimum expenditure of energy; and economy, as signifying the minimum expenditure of money consistent with the attainment of that result. The warranted degree of economy is a relative factor dependent upon the value of the result to be obtained. Good public service cannot be jeopardized by false or mistaken economy due to the disregard of all else but the effort to save money. The aim should be to attain the best public service at the least cost to the city.

The practical application of the principles of economy and efficiency necessitates the supervision of the various divisions of the department in order to ascertain: tirst, if work proposed or in progress is necessary for the effective operation of any function of the department; second, if work deemed necessary is accomplished under present conditions with efficiency; third, if a greater efficiency can be obtained by improved methods and the betterment of physical conditions; fourth, if such improvements will effect a greater economy in operation, consistent with efficient service. To allow of this supervision, and for the purpose of administrative study, summaries of detailed reports prepared in graphic form, when practicable, show the results of work accomplished throughout the department and the cost of operation in order that the principles of economy and 
efficiency may be scientifically applied. Such information must present concisely facts similar to those available for the use of the executive head of a successful commercial enterprise, for no administrative head must be wholly dependent on verbal statements of subordinates.

The proper distribution of expenditures to determine accurate costs incurred in the operation of the various functional divisions of the department along lines similar to those used in good commercial practice, is the basis of securing the information required by administrative officials. To accomplish this result, a Division of Costs and Statistics collects and tabulates the facts and data pertaining to the various activities of the department on a unit cost basis. For instance, the efficiency of a given pumping station is determined by the duty of a million foot pounds per hundred pounds of coal and the economy in cost per million gallon feet of water pumped. It will therefore be seen that the problems arising in connection with the work of the department are largely those of administration which require knowledge of operating conditions resulting from efficient organization and significant statistical information.

It has been necessary to reclassify the expenditures of the department on a functional basis in order that cost data may be properly distributed. This involves a summary of facts pertaining to the operation of the department segregated under administration, operation and maintenance.

Monthly, quarterly and annual reports are compiled by abstracting the totals of the columns in an analytical expense ledger in which all the information indicated by the classification of expenditures is summarized. The reports show in detail the cost to the department, of each function, sub-function or division of a sub-function, if any. The reports also include comparative figures for a corresponding prior period, month, quarter or year, the accumulated figures to date, or both, as the case may be. Extra typewritten carbon copies of the reports are made, and the sections showing the detailed expenditures of each bureau and division are sent to the respective administrative heads. The sheet for pumping division, for example, on which appears the cost of operation and maintenance of pumping stations, is sent to the chief engineer and the division engineer in charge of pumping stations. A system for obtaining the cost and efficiency of each pumping station is also in use. This system applies to all 
divisions of the department which have to do with operation and maintenance and allows of the following information being obtained:

(1) The cost of each division of a sub-function, e. g., cost of each pumping station.

(2) The cost of each job or unit cost, e. g., the cost of a repair job in a pumping station.

(3) The itemized cost of each job.

All of the information necessary for the analysis of expenditures, including the costs and statistics records, is based upon and compiled from the expenditure vouchers and pay rolls, the stores control system, and the time and service records.

In addition to the reports already described, monthly statements are sent to the several administrative heads of the department. These statements contain the amount of expenditures as well as encumbrances on account of each appropriation or other fund authorized and the balances unencumbered.

The object of all the records which have been described is to secure the accurate costs of the department for the purpose of intelligent administration and of obtaining proper estimates for appropriations and other funds.

The department collects the water revenue of the city, and deposits it to the credit of the City Chamberlain, who acts as the treasurer, vouchers are submitted to the Department of Finance for audit and approval, after which they are sent to the City Chamberlain for payment. It is necessary, however, that the administrative officers of the department have the information as to the revenue side of the accounting as well as expenditures, and the following is therefore prepared:

\section{Revenue Account or Annual Statement of Income and Expenditures}

(1) The Revenue of the Department.

(2) The Expense of Operating the Department and maintaining its properties. This will include expenditures by others for the benefit of the Department, i. e.:

Interest and Sinking Fund Installments (Comptroller).

Rents-Sinking Fund Commission.

Legal-Corporation Counsel.

Printing and Stationery-(City Record).

(3) The Net Revenue Account. 
Finally the annual financial statement of the department shows its assets and liabilities.

The Department of Water Supply, Gas and Electricity represents an estimated investment by the City of New York of over $\$ 300,000,000$ and is one of the most important divisions of the municipal government.

It supplies the city with more than $500,000,000$ gallons of water daily and bears the responsibility of maintaining a constant and abundant supply. It safeguards the lives of over $5,000,000$ people by protecting the supply against contamination. It has jurisdiction over an area, including the watersheds, of more than 600 square miles, and also over the aqueducts and the numerous storage reservoirs. It operates the high pressure fire stations and maintains and supervises the extension of this service.

The entire street and park lighting of the city, the lighting, heating and power service of municipal buildings, and the testing of the gas supplied to consumers comes under the supervision of the department, together with the inspection of 10,000 illuminated signs and over 550 theaters. The expenditure incurred in lighting the 77,000 street lamps within the city limits amounts to $\$ 5,000,000$ annually.

As a revenue collecting function of the city the department is second in importance to the office of the Receiver of Taxes. The total revenue or charges for water consumed in the year 1911 amounted to $\$ 14,420,000$. This fact gives the department a singular position as compared with the other divisions of the city government. The substantial revenue of the department, considerably in excess of its expenditures, places it on the self-sustaining basis of a profitable commercial enterprise.

The importance and the responsibility of these public services entrusted to the department and the duty to the taxpayer call for administration along business lines, that is, with economy, and efficiency.

The department, through the efforts of its administrative heads, has accomplished many economies and has also attained a higher degree of efficiency in various branches of its work.

One of the most important features of efficiency is to promote the personal efficiency of the individual employee. This is accomplished by means of service records which show the degree of proficiency in 
the performance of his duties, allows the acknowledgment of efficient service, discloses inefficiency, and places responsibility.

Inequality in clerical work with respect to compensation results in discontent and inefficiency on the part of the individual employees and, in consequence, positions are graded with respect to the character of work irrespective of incumbents.

Special effort has been made to create a feeling of co-operation among the individuals of the different branches of the department and to prevent the work from acquiring the reputation of being an investigation solely for the detection of inefficiency. The most effectual betterment of conditions is dependent upon the earnest co-operation of every employee of the department.

In the year 1910 the per capita consumption of water for New York City was placed at 127 gallons per day. Through the vigorous campaign against water waste resulting from the efforts of the department to conserve water during the protracted droughts of 1910 and 1911, the daily per capita consumption was reduced to $93 \frac{1}{2}$ gallons This gives New York City a lower per capita consumption than any city in the country of over 400,000 population, with the exception of San Francisco. This important economy was accomplished by a house to house inspection for the purpose of discovering leaking fixtures and by the use of the pitometer to determine the presence of leaks in mains. Direct appeal was made to the individual consumers through means of a pamphlet, widely circulated by the depart. ment, illustrating leaks caused by carelessness, poor workmanship and faulty material used in plumbing fixtures. The pamphlet emphasized the fact that a leaking faucet wastes annually from $\$ 2.00$ to $\$ 6.00$ worth of water, while water flowing through an opening the size of the eye of a needle $\frac{1}{32}$ in. in diameter and under a pressure of thirty-nine pounds will amount, on a meter rate basis, to $\$ 11.68$ annually. These examples showed the large amount of water wasted through small leaks where the general idea is that they are too insignificant to warrant attention. Considerable attention was also given to leaks resulting from bad condition of service pipes and house fixtures, owing to the effect of corrosion, damage to pipe by unequal settlement, badly wiped joints, and electrolysis.

The issuance of this pamphlet was the first attempt on the part of the city to educate the public in the cost of water and to solicit the co-operation of consumers to the necessity of checking waste. 
Since the water waste fetection work was started in the year 1910 , leaks from which water was going to waste that would be worth, at meter rates, over $\$ 3,000,000$ have been stopped. It has cost the taxpayer only a little over $\$ 75,000$ to accomplish this result.

By the addition of one hour to the working day for the department, affecting over 700 employees, the total number of work days was increased over sixteen per cent, equivalent to thirty-five additional working days for each employee per annum, or a total of nearly 25,000 additional working days yearly.

The consolidation of the Bureau of Water Supply, under one head instead of under six independent heads, as formerly, resulted in a yearly reduction in salaries of about $\$ 300,000$, and in the elimination of proposed works which would have cost the city about $\$ 1,800$,000 . The substitution of other work effected an annual economy in operating and maintenance charges of $\$ 200,000$.

In the year 1909 the cost of coal consumed by the department amounted to $\$ 613,806$. The cost of coal in 1910 was $\$ 491,292$, showing a saving of $\$ 122,514$, over the cost for the previous year, a condition which resulted from more economical and efficient means of purchasing and handling coal. In addition, there was 2.5 per cent more water pumped in 1910 than during the previous year. Standard specifications and contracts for coal have been adopted. A complete system applying to the inspection, weighing, sampling, analysis, and delivery and payment and also as to consumption of coal was installed.

The reduction in the annual cost of street lighting enabled the department to appropriate this saving to light a number of new avenues.

Through a complete reorganization in the Bureau of Water Register, the installation of improved methods and procedures, and the attainment of an increased efficiency in the work of the bureau, the revenue of the city was increased from $\$ 10,652,213.89$ in 1909 to $\$ 14,420,000$ in the year 1911. By a careful investigation and study of the clerical methods employed by this bureau, work was redistributed equitably to secure the maximum obtainable from each individual with the result that twice as many accounts can now be handled in the meter reading division, notwithstanding the increase of work due to the more frequent reading of meters, which caused the work to be doubled. A new system of inspection has also been 
installed which allows this work to be carefully checked and recorded while inspectors can be located at any time while on their rounds of inspection. This work is periodically tested and compared to see that the maximum personal efficiency is being obtained.

A substantial annual saving to the department is the result of the establishment of a Bureau of Supplies. This was accomplished by the more economical purchase of materials, the standardization of supplies, and the formulation of improved specifications, together with the more efficient methods due to the centralization of storing

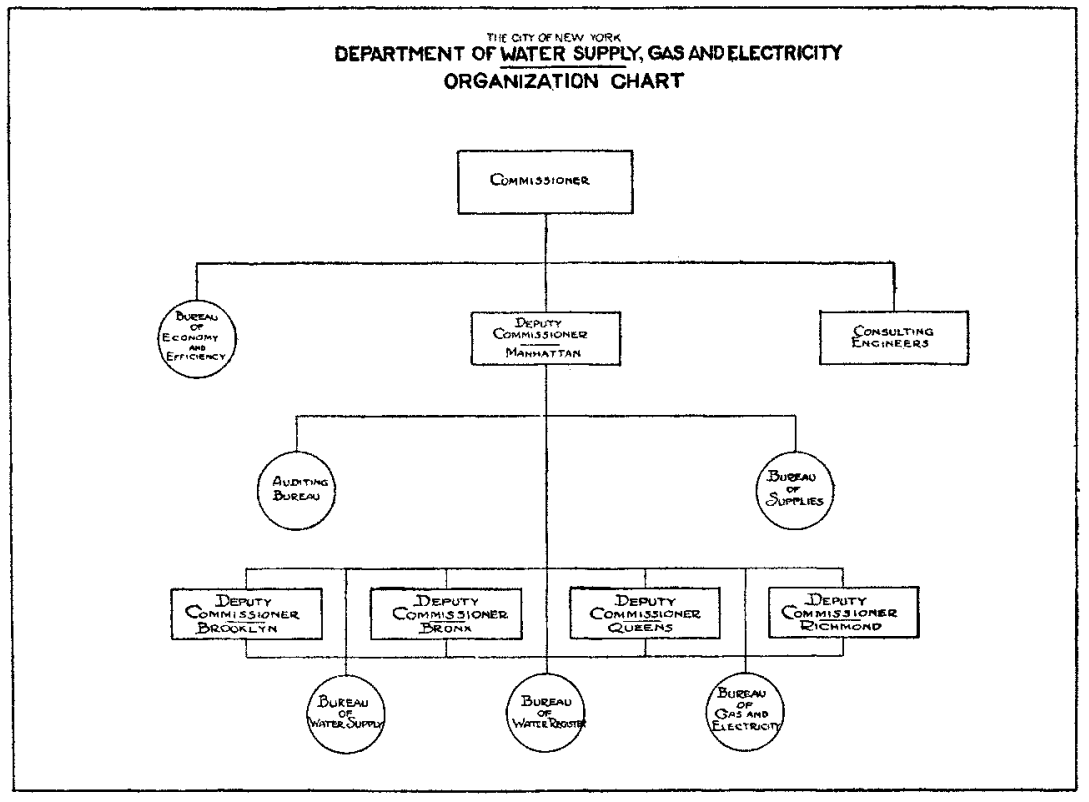

and distributing supplies along lines comparable with the most improved methods practiced in large industrial enterprises.

The complete and improved system of filling out pay rolls by mechanical means reduced the time required to fill out one pay roll sheet from twenty-five minutes to twenty-five seconds.

The application of the principles of economy and efficiency to the operation of the department, some of which have been enumerated in the previous paragraphs, illustrates the great value of this character of work to the city. Sustained effort along these lines promises to 
accomplish further improvements. The appreciation of this fact by Commissioner Henry S. Thompson caused him to establish a new division of the department, known as the Bureau of Economy and Efficiency, devoted wholly to this special character of work. The bureau is a separate branch of the department and its official head reports direct to the Commissioner. Its staff of employees consists of experts in accounting and engineering through whose efforts are made critical analyses of operating methods of the department.

The bureau will keep pace with advances in methods adopted by commercial organizations, with the idea of applying them to the operation of the department. A library, consisting of bulletins and pamphlets and reports published by the federal and municipal governments, is being collected. This gives access to any information collected by others which may be of value to the department.

The exact saving to the department to be obtained from the new bureau is a difficult matter to prophesy and cannot be calculated in dollars and cents. It is generally conceded that the business operated on scientific principles of practical utility is the one that attains the greatest commercial success, and the essentials of economy and efficiency affecting this result are applicable to municipal work and especially to this department. 